\title{
Discrimination of the notifiable pathogen Gyrodactylus salaris from G. thymalli (Monogenea) using statistical classifiers applied to morphometric data
}

\author{
E. S. $\mathrm{MCHUGH}^{1}$, A. P. SHINN ${ }^{2 *}$ and J. W. $\mathrm{KAY}^{1}$ \\ ${ }^{1}$ Department of Statistics, University of Glasgow, Glasgow G12 8QQ, Scotland, UK \\ ${ }^{2}$ Institute of Aquaculture, University of Stirling, Stirling FK9 4LA, Scotland, UK
}

(Received 5 November 1999; revised 23 March 2000; accepted 23 March 2000)

SUMMARY

The identification and discrimination of 2 closely related and morphologically similar species of Gyrodactylus, G. salaris and $G$. thymalli, were assessed using the statistical classification methodologies Linear Discriminant Analysis (LDA) and $k$-Nearest Neighbours (KNN). These statistical methods were applied to morphometric measurements made on the gyrodactylid attachment hooks. The mean estimated classification percentages of correctly identifying each species were $98.1 \%(\mathrm{LDA})$ and $97.9 \%(\mathrm{KNN})$ for G. salaris and $99.9 \%(\mathrm{LDA})$ and $73.2 \%(\mathrm{KNN})$ for G. thymalli. The analysis was expanded to include another 2 closely related species and the new classification efficiencies were $94 \cdot 6 \%$ (LDA) and $98 \cdot 0 \%$ (KNN) for G. salaris; $98.2 \%(\mathrm{LDA})$ and $72.6 \%$ (KNN) for G. thymalli; $86.7 \%$ (LDA) and $91 \cdot 8 \%$ (KNN) for G. derjavini; and $76.5 \%(\mathrm{LDA})$ and $77.7 \%(\mathrm{KNN})$ for G. truttae. The higher correct classification scores of G. salaris and $G$. thymalli by the LDA classifier in the 2-species analysis over the 4-species analysis suggested the development of a 2 stage classifier. The mean estimated correct classification scores were $99.97 \%$ (LDA) and $99.99 \%$ (KNN) for the $G$. salaris-G. thymalli pairing and $99.4 \%$ (LDA) and $99 \cdot 92 \%$ (KNN) for the G. derjavini-G. truttae pairing. Assessment of the 2-stage classifier using only marginal hook data was very good with classification efficiencies of $100 \%$ (LDA) and $99.6 \%(\mathrm{KNN})$ for the G. salaris-G. thymalli pairing and $97 \cdot 2 \%(\mathrm{LDA})$ and $99 \cdot 2 \%$ (KNN) for the G. derjavini-G. truttae pairing. Paired species were then discriminated individually in the second stage of the classifier using data from the full set of hooks. These analyses demonstrate that using the methods of LDA and KNN statistical classification, the discrimination of closely related and pathogenic species of Gyrodactylus may be achieved using data derived from light microscope studies.

Key words: Gyrodactylus, Monogenea, Gyrodactylus salaris, statistical classifiers, linear discriminant analysis, k-nearest neighbours.

\section{INTRODUCTION}

The reports and, in certain cases, misidentifications of Gyrodactylus salaris Malmberg, 1957 from fish stocks from a number of neighbouring European countries (see Table 1), is justifiably cause for concern to the UK's G. salaris-free status. While Shinn, Sommerville \& Gibson's (1995) study of 234 salmonid sites throughout the UK and Platten, McLoughlin \& Shinn's (1994) survey of 17 fish farms and 7 rivers in Northern Ireland demonstrated the British salmonid stocks to be $G$. salaris-free, the gyrodactylid fauna of British thymallids was at that time unknown. A survey of grayling, Thymallus thymallus L., in 9 English rivers during the period 1995-1996 by Denham \& Long (1999) found that grayling from 6 of these rivers were infected with $G$. thymalli Zitnan, 1960. The impact $G$. salaris has had on fish stocks throughout Norway has warranted the development of techniques for its identification from

\footnotetext{
* Corresponding author: Institute of Aquaculture, University of Stirling, Stirling FK9 4LA, Scotland. Tel: +44 1786473171 . Fax: + 441786472133 .

E-mail: aps1@stir.ac.uk
}

other and relatively benign close relatives. Using the nucleotide sequence of the srRNA V4 region, Cunningham et al. (1995) demonstrated the discrimination of G. salaris from 2 species of Gyrodactylus, G. derjavini Mikailov, 1975 and G. truttae Gläser, 1974, commonly occurring on European salmonids. There was, however, no variation in the 150 base nucleotide sequence between $G$. salaris and G. thymalli. Cunningham et al. (1995) concluded that while the $\mathrm{V} 4$ region may not provide the information necessary to discriminate these 2 morphologically similar species, other variable regions of the genome may. G. thymalli and its discrimination from $G$. salaris represents a problem within gyrodactylid taxonomy. Malmberg (1987b) suggested that forms of the 2 species found on certain salmonid hosts are morphologically similar as shown by Fig. 1 (see also Mo \& Appleby, 1990; Shinn et al. 1995; Denham \& Long, 1999); and work by Bakke (1991) and Bakke \& Jansen (1991) on the experimental cross-transfer of $G$. salaris and $G$. thymalli between their recognized fish hosts found that both species of Gyrodactylus were able to survive and reproduce. Later, in 1994, Mo's (1994) exam- 
Table 1. Reports of Gyrodactylus salaris in Northern Europe

\begin{tabular}{ll}
\hline \hline Report of G. salaris & Reference \\
\hline Bosnia-Herzegovina & Imamovic (1987) \\
Czechoslovakia & Ergens (1961)*; Rehulka (1973)† \\
Denmark & Malmberg (1973) \\
Finland & Rimaila-Pärnänen \& Wiklund (1987) \\
France & Johnston, MacKenzie, Cunningham, Eiras \& Bruno \\
& $(1996)$ \\
Germany & Schmahl (1988); Lux (1990) \\
Karelia & Ieshko, Berland, Shulman, Bristow \& Shurov (1995) \\
Norway & Malmberg (1973) \\
Portugal & Johnston, MacKenzie, Cunningham, Eiras \& Bruno \\
& $(1996)$ \\
Russia & Ergens (1983) †; Rumyantsev (1989) \\
Scotland & Campbell (1974)§ \\
Slovakia & Zitnan (1974) \\
Spain & Santamarina, Tojo, Ubeira, Quinteiro \& Sanmartin \\
& $(1991)$ \\
Sweden & Malmberg (1957) \\
Ukraine & Tesarcik \& Ivasik (1974) \\
Yugoslavia & Kulakovskaya (1967) \\
\hline \hline
\end{tabular}

* Believed by Tanum (1983) to be another species not G. salaris.

$\uparrow$ Believed by Mo (1983) to be G. truttae, however, Malmberg (1987c) believes that $G$. truttae is also erroneous but Rehulka's specimens resemble another Gyrodactylus sp. closely related to G. salaris.

$\ddagger$ Recorded as Gyrodactylus sp. but suggested by Malmberg (1987b) to most probably represent $G$. salaris.

$\S$ Mis-identification, more likely to be G. derjavini or G. truttae.

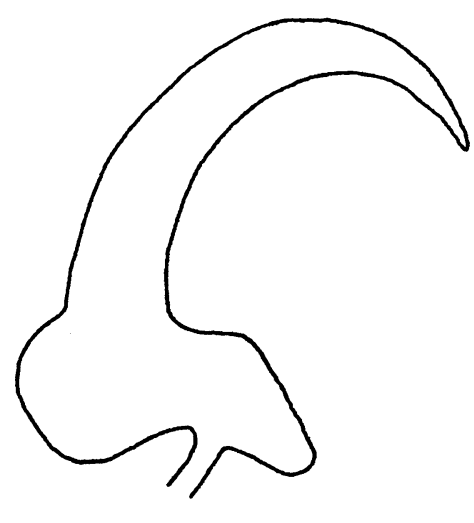

A
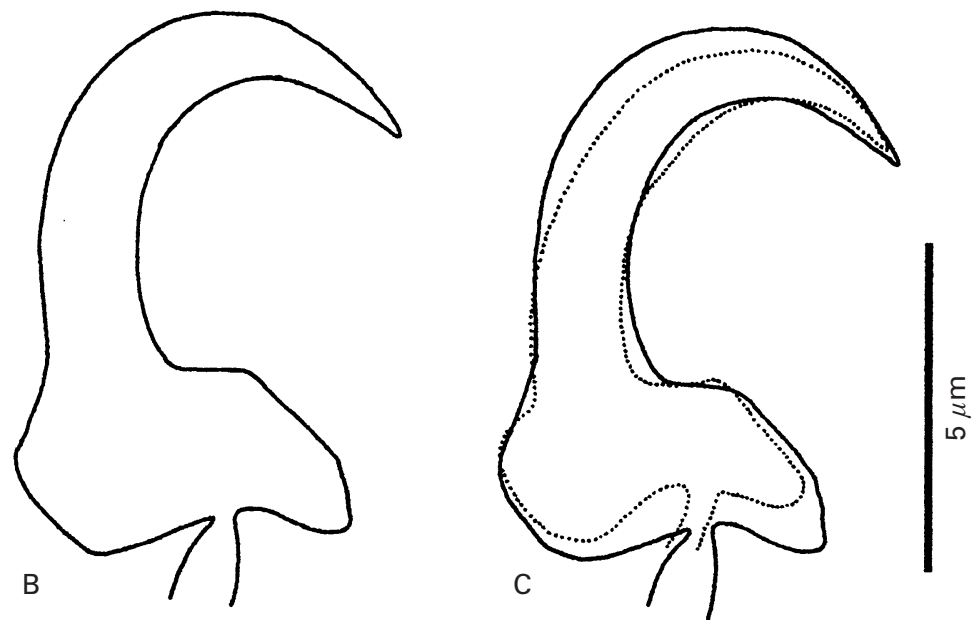

Fig. 1(A) Marginal hook sickle of Gyrodactylus thymalli Zitnan, 1960 collected from Thymallus thymallus in the River Test, UK in April 1997. (B) Marginal hook sickle of G. salaris Malmberg, 1957 collected from Salmo salar in the River Ätran (Nydale), Sweden in April 1992. (C) Overlay of the G. salaris marginal hook sickle (solid line) with that of $G$. thymalli (dotted line) to show differences in hook morphology.

ination of variation in the morphology of the opisthaptoral sclerites of $G$. salaris between localities sampled led him to consider that the form of $G$. salaris on rainbow trout was indistinguishable from the sclerites of $G$. thymalli.

An investigation by Kay, Shinn \& Sommerville (1999) demonstrated the potential for the use of modern statistical classifiers in differentiating species of the genus Gyrodactylus. The study applied 2 statistical methods, nearest neighbours and linear discriminant analysis, to data derived from light microscope images of the opisthaptoral hooks. This approach resulted in the perfect discrimination of $G$. salaris from other closely related species. The current study investigates the ability of these 2 statistical classification methodologies to discriminate $G$. salaris from $G$. thymalli and the latter species from other gyrodactylids parasitizing salmonids. The notion of a suggested synonomy of $G$. thymalli with $G$. salaris that could potentially invalidate the $G$. salaris-free status of the UK or that present methodologies may give rise to false positives with regard to 
the identification of $G$. salaris is worrying. Serious consequences could stem from inaccurate species determinations either as $G$. salaris being misidentified as $G$. thymalli and thus allowing $G$. salaris to go unchecked in the environment or, G. thymalli being identified as $G$. salaris and costly treatments being implemented to contain and prevent its spread. Both errors could have serious impacts on fish communities and their environment.

\section{MATERIALS AND METHODS}

\section{Specimen collection and preparation}

Specimens of Gyrodactylus von Nordmann, 1832 parasitizing salmonids collected during the 19901992 survey conducted by Shinn et al. (1995) were re-analysed in conjunction with specimens of $G$. salaris Malmberg, 1957 and G. thymalli Zitnan, 1960. Details pertaining to the sites of collection for the 134 specimens of G. truttae, 1974 and $254 G$. derjavini Mikailov, 1975 taken during the survey have been given by Shinn, Kay \& Sommerville (2000). Ten specimens of $G$. thymalli parasitizing Thymallus thymallus in the River Test, Hampshire, England were collected in April 1997 and provided for this study by Dr K. L. Denham (CEFAS). The British gyrodactylid material was compared to 85 specimens of $G$. salaris collected from Salmo salar from various watercourses across Scandinavia by $\mathrm{Dr}$ G. Malmberg (University of Stockholm, Sweden) and Professor T. A. Bakke (Zoological Museum, University of Oslo, Norway) throughout the 19901992 time-period. All the gyrodactylid material was prepared for light microscopy, mounted in ammonium picrate glycerine, according to the methodology given by Malmberg (1957).

Morphometric data on the attachment hooks were collected from slide preparations of Gyrodactylus using an eye-piece graticule at $\times 100$, oil immersion on a BH2 Olympus binocular microscope with phase-contrast. Ten point to point morphometric measurements were made, 3 from the hamulus (total length, shaft length and point length), 2 from the ventral bar (total length and total width) and 5 from the marginal hook (total length, shaft length, sickle length, sickle proximal width and sickle distal width). Using the marginal hook numbering system of Llewellyn (1970), marginal hook number 8 was measured on each individual gyrodactylid. Where this was not possible, then marginal hook number 7 was measured.

\section{Statistical methods}

Various statistical classification techniques were used to build classification rules and to assess their likely performance in the classification of new specimens (McLachlan, 1992).

Canonical variate plots were constructed in each case in order to visualize the data with respect to the canonical variate axes. These are determined by the linear functions of the measurements which best separate the different classes. The canonical variates may be used to classify objects into one of the classes. When there are 2 classes, there is just 1 canonical variate and when there are 4 classes there are 3 canonical variates.

The method of Linear Discriminant Analysis (LDA) was used to estimate a classification rule; when it is used just for classification this method is identical to the use of canonical variates. Because the specimens which are available for analysis are not necessarily representative of the naturally-occurring frequencies, and particularly because the number of $G$. thymalli specimens is small relative to the other types, it was assumed a priori that the class probabilities are equal. In the absence of precise relevant information of the relative costs of misclassifications, it was assumed that these costs are equal; this results in specimens being allocated to the most likely class on the basis of the measurements. The method of $k$-Nearest Neighbours (KNN) was also used in each case, and this provides a completely non-parametric approach which allows non-linear boundaries to be fitted between the classes. In the applications described herein, 3 nearest neighbours were used.

The method of repeated, stratified, 5-fold crossvalidation was used to assess the generalization error likely to be obtained when a classifier is applied to new specimens. In this approach the available specimens are split randomly into 5 groups in proportion to the numbers of each type that are available. One of the 5 groups of data is held back to form a test set, and the remaining data are used to build the classifier. The resulting rule is then applied to the test set and the predictions obtained for each test specimen are compared with the true types; thus the number of misclassifications are calculated. This procedure is repeated taking, in turn, each of the other 4 groups to be the test set, and the numbers are combined to form an overall estimate of the rates of correct classification and also each type of misclassification. This method makes efficient use of the available data. This entire procedure was then repeated 100 times and the mean and range of the resulting estimates of the classification percentages were computed.

The analyses were conducted using scripts using public-domain software provided (Venables \& Ripley, 1997) for the S-PLUS statistical package (SPLUS 4, 1997).

\section{RESULTS}

Discrimination of $\mathrm{G}$. salaris and $\mathrm{G}$. thymalli

A canonical variate plot was constructed using all 10 measurements taken from the $10 \mathrm{G}$. thymalli 


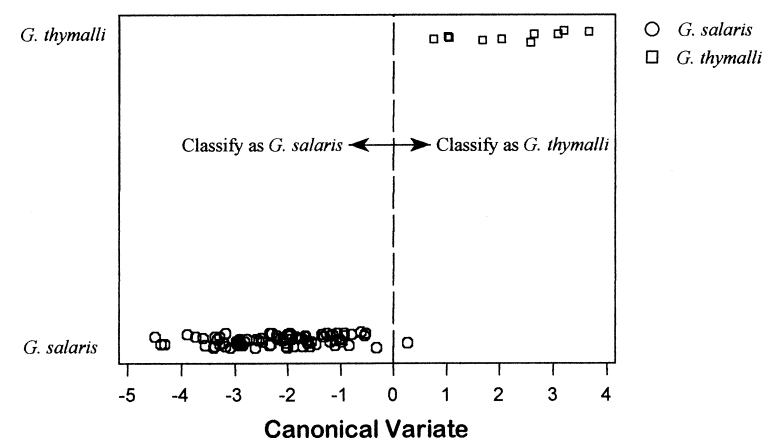

Fig. 2. Canonical variate plot of morphometric data from the species Gyrodactylus salaris and G. thymalli.

specimens and the 85 G. salaris specimens and this is displayed in Fig. 2. It is clear that there is very good separation between the classes and that this method produces only 1 misclassification $(G$. salaris as $G$. thymalli) when applied to these 'training' specimens. Of course, as the aim would be to use the classification rule on new specimens we need to assess the predictive ability of this classification rule. The method of repeated, stratified, 5-fold cross-validation was used to estimate the misclassification rates likely to be found with new specimens. The results are given in Table 2.

Using the LDA classifier we may estimate that $98.1 \%$ of G. salaris specimens would be classified correctly as being $G$. salaris and $99.9 \%$ of $G$. thymalli specimens would be classified correctly as being G. thymalli (on average); also $1.9 \%$ of $G$. salaris specimens would be misclassified as being $G$. thymalli and $0.1 \%$ of $G$. thymalli specimens would be misclassified as being G. salaris. The results obtained using the KNN method are similar to the LDA results for $G$. salaris, but not as good for $G$. thymalli.

\section{Discrimination of the 4 species}

The canonical variate plot using the first 2 canonical axes and based on all 10 measurements taken from the specimens of G. salaris, G. thymalli, G. derjavini and G. truttae is shown in Fig. 3. The most striking feature of the plot is that $G$. thymalli is most similar to $G$. salaris and that these 2 types are clearly separated from $G$. derjavini and G. truttae; these

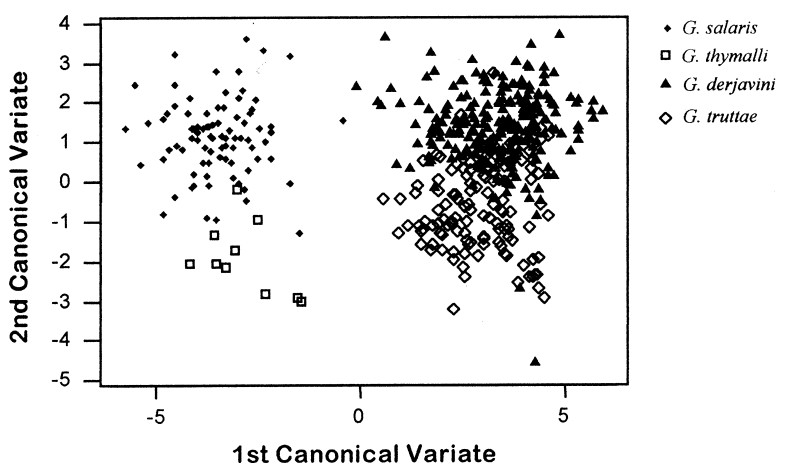

Fig. 3. Canonical variate plot of morphometric data from the 4 species of Gyrodactylus ( $G$. derjavini, $G$. salaris, G. thymalli and G. truttae).

latter 2 types show a fair degree of overlap. The predictive ability of the classifiers for all 4 types was assessed using repeated, stratified, 5-fold crossvalidation and the results are given in Table 3.

With the LDA method we may estimate that $94.6 \%$ of G. salaris specimens, $98.2 \%$ of G. thymalli specimens, $86.7 \%$ of $G$. derjavini specimens and $76.5 \%$ of G. truttae specimens, respectively, would be classified correctly. With the KNN method, the corresponding percentages are 98.0, 72.6, 91.8, $77.7 \%$. Hence the KNN method is likely to perform better for the G. salaris, G. derjavini and G. truttae specimens, although overall LDA is better for the discrimination of $G$. salaris and $G$. thymalli and $\mathrm{KNN}$ is better for the discrimination of $G$. derjavini and $G$. truttae. Table 3 shows also the percentages of the various types of misclassification; the main problem lies in the confusion between $G$. derjavini and $G$. truttae, although with the KNN method there is confusion between $G$. thymalli and $G$. salaris. It is clear that there is very little confusion between the pairing G. salaris-G. thymalli and the pairing G. derjavini-G. truttae.

\section{A 2-stage classifier}

Given the results obtained in the previous 2 subsections, namely that (a) the LDA results are better for discrimination of G. salaris and G. thymalli in the 2-class case than in the 4-class case and (b) the pairings $G$. salaris $-G$. thymalli and $G$. derjavini-G. truttae are clearly separated from each other, it seems

Table 2. Estimated classification percentages for the discrimination of Gyrodactylus salaris and G. thymalli using the LDA and KNN methods of classification

\begin{tabular}{|c|c|c|c|c|c|c|}
\hline \multirow[b]{2}{*}{ Classification } & \multicolumn{3}{|l|}{ LDA } & \multicolumn{3}{|l|}{$\mathrm{KNN}$} \\
\hline & Mean & Min & Max & Mean & Min & Max \\
\hline G. salaris as G. salaris & $98 \cdot 1$ & $95 \cdot 3$ & $98 \cdot 8$ & 97.9 & $95 \cdot 3$ & $100 \cdot 0$ \\
\hline G. salaris as $G$. thymalli & 1.9 & $1 \cdot 2$ & $4 \cdot 7$ & $2 \cdot 1$ & $0 \cdot 0$ & $4 \cdot 7$ \\
\hline G. thymalli as $G$. salaris & $0 \cdot 1$ & $0 \cdot 0$ & $10 \cdot 0$ & $26 \cdot 8$ & $20 \cdot 0$ & $30 \cdot 0$ \\
\hline G. thymalli as $G$. thymalli & 99.9 & $90 \cdot 0$ & $100 \cdot 0$ & $73 \cdot 2$ & $70 \cdot 0$ & $80 \cdot 0$ \\
\hline
\end{tabular}


Table 3. Estimated classification percentages for the discrimination of Gyrodactylus salaris, G. thymalli, $G$. derjavini and $G$. truttae using the LDA and KNN methods of classification

\begin{tabular}{|c|c|c|c|c|c|c|}
\hline \multirow[b]{2}{*}{ Classification } & \multicolumn{3}{|l|}{ LDA } & \multicolumn{3}{|l|}{$\mathrm{KNN}$} \\
\hline & Mean & Min & Max & Mean & Min & Max \\
\hline G. salaris as G. salaris & $94 \cdot 6$ & $91 \cdot 8$ & $96 \cdot 5$ & $98 \cdot 0$ & $96 \cdot 5$ & $100 \cdot 0$ \\
\hline G. salaris as $G$. thymalli & $5 \cdot 2$ & $3 \cdot 5$ & $8 \cdot 2$ & $2 \cdot 0$ & $0 \cdot 0$ & $3 \cdot 5$ \\
\hline G. salaris as $G$. derjavini & $0 \cdot 2$ & $0 \cdot 0$ & $1 \cdot 2$ & $0 \cdot 0$ & $0 \cdot 0$ & $0 \cdot 0$ \\
\hline$G$. salaris as $G$. truttae & $0 \cdot 0$ & $0 \cdot 0$ & $0 \cdot 0$ & $0 \cdot 0$ & $0 \cdot 0$ & $0 \cdot 0$ \\
\hline G. thymalli as $G$. salaris & $1 \cdot 8$ & $0 \cdot 0$ & $10 \cdot 0$ & $27 \cdot 4$ & $20 \cdot 0$ & $30 \cdot 0$ \\
\hline G. thymalli as G. thymalli & $98 \cdot 2$ & $90 \cdot 0$ & $100 \cdot 0$ & $72 \cdot 6$ & $70 \cdot 0$ & $80 \cdot 0$ \\
\hline G. thymalli as $G$. derjavini & $0 \cdot 0$ & $0 \cdot 0$ & $0 \cdot 0$ & $0 \cdot 0$ & $0 \cdot 0$ & $0 \cdot 0$ \\
\hline G. thymalli as G. truttae & $0 \cdot 0$ & $0 \cdot 0$ & $0 \cdot 0$ & $0 \cdot 0$ & $0 \cdot 0$ & $0 \cdot 0$ \\
\hline$G$. derjavini as $G$. salaris & $0 \cdot 3$ & $0 \cdot 0$ & $2 \cdot 8$ & $0 \cdot 1$ & $0 \cdot 0$ & $0 \cdot 8$ \\
\hline$G$. derjavini as $G$. thymalli & $0 \cdot 0$ & $0 \cdot 0$ & $0 \cdot 0$ & $0 \cdot 0$ & $0 \cdot 0$ & $0 \cdot 0$ \\
\hline G. derjavini as G. derjavini & $86 \cdot 7$ & $82 \cdot 9$ & $91 \cdot 2$ & $91 \cdot 8$ & $86 \cdot 8$ & $94 \cdot 8$ \\
\hline$G$. derjavini as $G$. truttae & $13 \cdot 0$ & $8 \cdot 8$ & $17 \cdot 1$ & $8 \cdot 1$ & $5 \cdot 2$ & $13 \cdot 1$ \\
\hline$G$. truttae as $G$. salaris & $0 \cdot 0$ & $0 \cdot 0$ & $0 \cdot 0$ & $0 \cdot 0$ & $0 \cdot 0$ & $0 \cdot 0$ \\
\hline$G$. truttae as $G$. thymalli & $0 \cdot 0$ & $0 \cdot 0$ & $0 \cdot 0$ & $0 \cdot 0$ & $0 \cdot 0$ & $0 \cdot 0$ \\
\hline$G$. truttae as $G$. derjavini & $23 \cdot 5$ & $19 \cdot 4$ & $26 \cdot 9$ & $22 \cdot 3$ & $18 \cdot 7$ & $26 \cdot 9$ \\
\hline G. truttae as G. truttae & $76 \cdot 5$ & $73 \cdot 1$ & $80 \cdot 6$ & $77 \cdot 7$ & $73 \cdot 1$ & $81 \cdot 3$ \\
\hline
\end{tabular}

Table 4. Estimated classification percentages for the discrimination of the 2 hybrid pairings Gyrodactylus salaris-G. thymalli (SalThy) and G. derjavini-G. truttae (DerjTrut) using the LDA and KNN methods of classification

\begin{tabular}{|c|c|c|c|c|c|c|}
\hline \multirow[b]{2}{*}{ Classification } & \multicolumn{3}{|l|}{ LDA } & \multicolumn{3}{|l|}{$\mathrm{KNN}$} \\
\hline & Mean & Min & Max & Mean & Min & Max \\
\hline SalThy as SalThy & $99 \cdot 97$ & $98 \cdot 9$ & $100 \cdot 0$ & 99.99 & 98.9 & $100 \cdot 0$ \\
\hline SalThy as DerjTrut & $0 \cdot 03$ & $0 \cdot 0$ & $1 \cdot 1$ & $0 \cdot 01$ & $0 \cdot 0$ & $1 \cdot 1$ \\
\hline DerjTrut as SalThy & $0 \cdot 6$ & $0 \cdot 3$ & $1 \cdot 8$ & $0 \cdot 08$ & $0 \cdot 0$ & $0 \cdot 3$ \\
\hline DerjTrut as DerjTrut & $99 \cdot 4$ & $98 \cdot 2$ & $99 \cdot 7$ & 99.92 & 99.7 & $100 \cdot 0$ \\
\hline
\end{tabular}

appropriate to consider a 2-stage classifier. In this classifier, the pairings $G$. salaris-G. thymalli and $G$. derjavini-G. truttae would be considered as 2 hyperclasses and the LDA and KNN methods applied to classify specimens into 1 of these 2 hyper-classes. If a specimen is classified as a $G$. salaris-G. thymalli hyper-class, the methods would be applied to just the data from the $G$. salaris and $G$. thymalli specimens to decide whether it is likely to be $G$. salaris or G. thymalli (as in Table 2 and Fig. 2). The method of repeated, stratified, 5-fold cross-validation was applied to all 10 measurements from the 95 G. salaris $-G$. thymalli specimens and the $385 G$. derjavini-G. truttae specimens and the results are given in Table 4.

With the LDA method, it may be estimated that $99.97 \%$ of specimens from the G. salaris - G. thymalli hyper-class and $99.4 \%$ of specimens from the $G$. derjavini-G. truttae hyper-class would be correctly classified. The corresponding percentages for the KNN method are $99.99 \%$ and $99.92 \%$. These results combined with those of Table 2 demonstrate that this 2-stage classifier based on the LDA method is likely to be very successful as long as future $G$. salaris and $G$. thymalli data are similar to the specimens considered here.

\section{Discrimination using subsets}

As described in the Materials and Methods section, the available measurements fall naturally into 3 subsets corresponding to the sclerite structures: the hamulus, the ventral bar and the marginal hook, and it is of interest to discover whether classification based on just a single sclerite structure is likely to be sufficiently accurate. Hence the cross-validation experiments which are described in the previous subsections were repeated for each of the 3 subsets. We now report on the experiments corresponding to the use of the 2-stage classifier. The results obtained with LDA and KNN for the hyper-classes are given in Table 5.

While in some cases, particularly with the marginal hook subset, the results are quite good they are not quite as good as those obtained using the full set of measurements. Similarly, the LDA and KNN 
Table 5. Estimated classification percentages for the discrimination of the 2 hybrid pairings Gyrodactylus salaris-G. thymalli and G. derjavini-G. thymalli using the LDA and KNN methods of classificationseparate analyses based on the sclerite subsets of the measurements

\begin{tabular}{|c|c|c|c|c|c|c|}
\hline \multirow[b]{2}{*}{ Classification } & \multicolumn{3}{|l|}{ LDA } & \multicolumn{3}{|l|}{$\mathrm{KNN}$} \\
\hline & Mean & Min & Max & Mean & Min & $\operatorname{Max}$ \\
\hline \multicolumn{7}{|l|}{ Hamulus } \\
\hline SalThy as SalThy & $96 \cdot 8$ & 96.8 & $96 \cdot 8$ & $93 \cdot 7$ & 91.6 & $96 \cdot 8$ \\
\hline SalThy as DerjTrut & $3 \cdot 2$ & $3 \cdot 2$ & $3 \cdot 2$ & $6 \cdot 3$ & $3 \cdot 2$ & $8 \cdot 4$ \\
\hline DerjTrut as SalThy & $3 \cdot 4$ & $3 \cdot 1$ & $3 \cdot 6$ & $0 \cdot 6$ & $0 \cdot 3$ & $1 \cdot 3$ \\
\hline DerjTrut as DerjTrut & $96 \cdot 6$ & $96 \cdot 4$ & $96 \cdot 9$ & $99 \cdot 4$ & $98 \cdot 7$ & $99 \cdot 7$ \\
\hline \multicolumn{7}{|l|}{ Ventral bar } \\
\hline SalThy as SalThy & $47 \cdot 6$ & $33 \cdot 7$ & $52 \cdot 6$ & $21 \cdot 6$ & 14.7 & $29 \cdot 5$ \\
\hline SalThy as DerjTrut & $52 \cdot 4$ & $47 \cdot 4$ & $66 \cdot 3$ & $73 \cdot 4$ & $70 \cdot 5$ & $85 \cdot 3$ \\
\hline DerjTrut as SalThy & $47 \cdot 9$ & $43 \cdot 6$ & $54 \cdot 0$ & $12 \cdot 8$ & $9 \cdot 4$ & $16 \cdot 1$ \\
\hline DerjTrut as DerjTrut & $52 \cdot 1$ & $46 \cdot 0$ & $56 \cdot 4$ & $87 \cdot 2$ & 83.9 & $90 \cdot 6$ \\
\hline \multicolumn{7}{|l|}{ Marginal hook } \\
\hline SalThy as SalThy & $100 \cdot 0$ & $100 \cdot 0$ & $100 \cdot 0$ & $99 \cdot 6$ & $96 \cdot 8$ & $100 \cdot 0$ \\
\hline SalThy as DerjTrut & $0 \cdot 0$ & $0 \cdot 0$ & $0 \cdot 0$ & $0 \cdot 4$ & $0 \cdot 0$ & $3 \cdot 2$ \\
\hline DerjTrut as SalThy & $2 \cdot 8$ & $2 \cdot 6$ & $2 \cdot 9$ & $0 \cdot 8$ & $0 \cdot 5$ & $1 \cdot 6$ \\
\hline DerjTrut as DerjTrut & $97 \cdot 2$ & $97 \cdot 1$ & $97 \cdot 4$ & $99 \cdot 2$ & $98 \cdot 4$ & $99 \cdot 5$ \\
\hline
\end{tabular}

Table 6. Estimated classification percentages for the discrimination of Gyrodactylus salaris and G. thymalli using the LDA and KNN methods of classification - separate analyses based on the sclerite subsets of the measurements

\begin{tabular}{|c|c|c|c|c|c|c|}
\hline \multirow[b]{2}{*}{ Classification } & \multicolumn{3}{|l|}{ LDA } & \multicolumn{3}{|l|}{$\mathrm{KNN}$} \\
\hline & Mean & Min & Max & Mean & Min & Max \\
\hline \multicolumn{7}{|l|}{ Hamulus } \\
\hline Salaris as Salaris & $88 \cdot 2$ & $84 \cdot 7$ & $89 \cdot 4$ & 98.8 & $97 \cdot 6$ & 98.8 \\
\hline Salaris as Thymalli & $12 \cdot 8$ & $10 \cdot 6$ & $15 \cdot 3$ & $1 \cdot 2$ & $1 \cdot 2$ & $2 \cdot 4$ \\
\hline Thymalli as Salaris & $19 \cdot 9$ & $10 \cdot 0$ & $20 \cdot 0$ & $49 \cdot 9$ & $40 \cdot 0$ & $50 \cdot 0$ \\
\hline Thymalli as Thymalli & $80 \cdot 1$ & $80 \cdot 0$ & $90 \cdot 0$ & $50 \cdot 1$ & $50 \cdot 0$ & $60 \cdot 0$ \\
\hline \multicolumn{7}{|l|}{ Ventral bar } \\
\hline Salaris as Salaris & $82 \cdot 4$ & $78 \cdot 8$ & 85.9 & 95.5 & $90 \cdot 6$ & $98 \cdot 8$ \\
\hline Salaris as Thymalli & $17 \cdot 6$ & $14 \cdot 1$ & $21 \cdot 2$ & $4 \cdot 5$ & $1 \cdot 2$ & $9 \cdot 4$ \\
\hline Thymalli as Salaris & $15 \cdot 1$ & $10 \cdot 0$ & $30 \cdot 0$ & $79 \cdot 7$ & $70 \cdot 0$ & $100 \cdot 0$ \\
\hline Thymalli as Thymalli & 84.9 & $70 \cdot 0$ & $90 \cdot 0$ & $20 \cdot 3$ & $0 \cdot 0$ & $30 \cdot 0$ \\
\hline \multicolumn{7}{|l|}{ Marginal hook } \\
\hline Salaris as Salaris & $90 \cdot 9$ & $87 \cdot 1$ & $94 \cdot 1$ & $99 \cdot 3$ & $97 \cdot 6$ & $100 \cdot 0$ \\
\hline Salaris as Thymalli & $9 \cdot 1$ & $5 \cdot 9$ & $12 \cdot 9$ & $0 \cdot 7$ & $0 \cdot 0$ & $2 \cdot 4$ \\
\hline Thymalli as Salaris & $15 \cdot 4$ & $0 \cdot 0$ & $20 \cdot 0$ & $21 \cdot 3$ & $20 \cdot 0$ & $30 \cdot 0$ \\
\hline Thymalli as Thymalli & $84 \cdot 6$ & $80 \cdot 0$ & 100.0 & $78 \cdot 7$ & $70 \cdot 0$ & $80 \cdot 0$ \\
\hline
\end{tabular}

methods were applied to the sclerite subsets for the G. salaris and G. thymalli classes and the results are given in Table 6; again the marginal hook subset shows the best performance but it is not quite as good as that obtained using the full set of measurements.

Again, while the results in individual cases are quite good, the level of likely accuracy is not high enough compared to that obtained with the full dataset.

\section{DISCUSSION}

Malmberg (1993) commented that the 'form' of $G$. salaris parasitizing Oncorhynchus mykiss (Walbaum) was reminiscent of $G$. thymalli and that the discrimination of such forms could only effectively be resolved by the collection and comparison of both species of Gyrodactylus from the full range of hosts and environmental conditions under which both species are found. Because of the scarcity of $G$. 
thymalli specimens available for this study, however, it has not been possible to encompass the full range of host and environmental variation for this species. For the comparator species G. salaris, material from a number of rivers, taken over a 15-month period, has been available for study and therefore provides a more satisfactory data-set. Whilst the present investigation has indicated clear differences between these species, it is nevertheless unwise to draw definitive conclusions until a larger sample of G. thymalli can be obtained.

Mo's (1991b) report of a species, tentatively identified as $G$. salaris, from $O$. mykiss cited differences from $G$. salaris taken from $S$. salar in terms of the possession of a stouter ventral bar and hamuli. In the same paper, no difference in the shape of the marginal hook was noted between these two morphs. In the present study it has not been possible, however, to obtain specimens of ' $G$. salaris' from $O$. mykiss and therefore the affinity of this species appears uncertain. The differences in shape between the marginal hook sickles of $G$. thymalli and $G$. salaris, however, are presented in Fig. $1 \mathrm{C}$ of the present study. While both sickles collected from the same month of the year are of a similar size, the marginal hook of G. salaris has a deeper foot to the sickle, the toe being noticeably broader. Both sickle points follow a similar curve but the sickle shaft and point of G. salaris are more robust. The variation in the size of the opisthaptoral sclerites of $G$. salaris with season was investigated by Mo $(1991 a, b, c)$, who found that the hooks were larger in colder water temperatures and smaller in warmer water temperatures. Variation in the shape of the sclerites with season was, however, less pronounced, the shape of the marginal hooks being notably constant. Regardless of season, the attachment hooks are fully developed at birth and undergo no further development or growth, only the hamulus root portion may continue to grow (Ergens, 1965; Malmberg, 1970).

Both G. salaris and G. thymalli belong to the $G$. salaris-group but are designated within different subgroups, their placement within these being based on the relative robustness of their hamuli and ventral bars (Malmberg, 1993). Whilst subtle differences in the shape of the marginal hook sickle, which are highlighted by the measurements used in the present study, allow experts to discriminate these species, it is questionable whether discrimination of these species may be achieved using univariate statistics on the classical point to point morphometrics gathered from the gyrodactylid attachment hooks.

The discrimination of gyrodactylid species has been achieved to a certain level in earlier studies using multivariate analyses such as principal components analysis (PCA) applied to morphometric data derived from specimens prepared for light microscopy (Shinn, 1994; Shinn et al. 1996) and on sonication liberated hooks examined using the scanning electron microscope (SEM) (Shinn, Gibson \& Sommerville, 1993; Shinn, 1994). While these studies allow for the discrimination of a species as a collective of individuals, however, the confidence that one might place upon the discrimination of an individual gyrodactylid is dependent upon its relative position in the PCA matrix and thus its position in relation to all other specimens within the analysis. Specimens positioned at the distal periphery of its species range in a PCA matrix might be clearly discriminated from another specimen situated on the distal periphery of its own species range but the confidence in discriminating 2 species diminishes where 2 species overlap. Thus it was not surprising that, where Gyrodactylus species were difficult to classify using conventional taxonomic procedures, the progression in gyrodactylid taxonomy and/or discrimination was to move away from methodologies with a numeric or morphometric basis to techniques with a molecular biology basis (Cunningham et al. 1995). However, Kay et al. (1999) and Shinn et al. (2000) established that the discrimination of closely related and morphologically similar Gyrodactylus species was possible using a variety of statistical classification approaches applied to morphometric data. The use of a statistical classification system once optimized and validated presents a rapid, reliable and cheap alternative to traditional methods and permits the early detection of pathogens from large numbers of samples.

This paper demonstrates with some success, the high correct percentage classifications of 2 closely related and morphologically similar species of Gyrodactylus, G. salaris (98.1\% LDA; $97.9 \% \mathrm{KNN})$ and G. thymalli $(99.9 \% \mathrm{LDA} ; 73.2 \% \mathrm{KNN})$, using 2 statistical classification methodologies, LDA and KNN. Expansion of the analysis to include additional species of Gyrodactylus illustrates that $G$. thymalli can also be discriminated from these (G. $\quad$ salaris $-94.6 \% \quad \mathrm{LDA} ; \quad 98.0 \% \quad \mathrm{KNN})$; (G. thymalli-98.2\% LDA; $72.6 \% \mathrm{KNN}) ;(G$. derjavini-86.7\% LDA; $91.8 \% \mathrm{KNN})$; and ( $G$. truttae $-76.5 \% \mathrm{LDA} ; 77.7 \% \mathrm{KNN}$ ). It is important to reiterate at this stage that the classification of these species is based upon relatively crude light-derived morphometric data i.e. 10 morphometric characters ( 3 hamulus, 2 ventral bar and 5 marginal hook). Thus by the addition of extra feature descriptors and/or by the development of algorithms for the detailed shape analysis of all or individual attachment hooks it would perhaps be possible to obtain better classification performance. The results from these early analyses illustrated that higher correct classification scores were obtained for G. salaris and $G$. thymalli by the LDA classifier in the 2 -species analysis over the 4-species analysis. Also, the clear discrimination of the morphologically similar $G$. salaris-G. thymalli $(99.97 \%$ LDA; $99.99 \% \mathrm{KNN})$ 
pairing from the G. derjavini-G. truttae $(99.4 \%$ LDA; $99.92 \% \mathrm{KNN}$ ) pairing proposed the development of a 2-stage classifier. When the individual attachment hooks were considered, the classification percentages for the marginal hook were equally good ( $G$. salaris-G. thymalli pairing $100 \%$ LDA, 99.6\% KNN; G. derjavini-G. truttae pairing $97.2 \% \mathrm{LDA}, 99.2 \% \mathrm{KNN}$ ) but not so for the other hook structures. While the benefits of using a 2-stage classifier are suggested here, a combined procedure working as an entire system is as yet to be evaluated, but it is clear that it would work well. Misclassifications, particularly in the case of G. salaris, would have serious consequences should they allow this species to slip through undetected. It is possible, however, to incorporate estimates regarding the relative seriousness of each type of misclassification into the classifier and thereby weight the discrimination to minimize more serious errors. For the purposes of this study no such estimates were built into the system, with the costs of the various types of misclassification assumed to be equal.

This work is promising, but more G. thymalli specimens are required in order to be more confident about the success of the application of our rules to new specimens. The high classification efficiencies are based on the data at hand and our estimates of likely future performance are contingent on the future data being similar to that of the present data. While G. thymalli material from a variety of hosts and environmental conditions was sought from national helminth collections across northern Europe, virtually no deposited material was available. The problem here is that with only $10 G$. thymalli specimens collected from a single locality, we must be cautious in our statement of discriminatory power.

The authors gratefully acknowledge for their valuable assistance in the collection of fish samples, Willie Yeomans and the Environment Agency and the numerous fish farms visited during the course of this study.

\section{REFERENCES}

BAKKE, т. A. (1991). A review of the inter- and intraspecific variability in salmonid hosts to laboratory infections with Gyrodactylus salaris Malmberg. Aquaculture 98, 303-310.

BAKKE, T. A. \& JANSEN, P. A. (1991). Susceptibility of grayling (Thymallus thymallus) to Gyrodactylus salaris Malmberg (Monogenea). Bulletin of the Scandinavian Society of Parasitology (Proceedings of the XVth Symposium of the Scandinavian Society for Parasitology) 1, 61.

CAMPBEll, A. D. (1974). The parasites of fish in Loch Leven. Proceedings of the Royal Society of Edinburgh, (1972-1973) 74, 347-364.

CUNNinghaM, C. O., McGillivray, D. M., MacKenZie, K. \& MELVIN, w. T. (1995). Identification of Gyrodactylus
(Monogenea) species parasitizing salmonid fish using DNA probes. Fournal of Fish Diseases 18, 539-544.

DENHAM, K. L. \& LONG, J. (1999). Occurrence of Gyrodactylus thymalli Zitnan, 1960 on grayling, Thymallus thymallus (L.), in England. Fournal of Fish Diseases 22, 247-252.

ERGENs, R. (1961). Zwei weitere Befunde der Gyrodactylus Art (Monogenoidea) aus der Tschechoslowakei. Vestnik Ceskoslovenské Spolecnosti Zoologické 25, 25-27.

ERGENs, R. (1965). Die Morphogenese der chitinoiden Teile des Haptors bei Gyrodactylus decorus Malmberg, 1956 (Monogenoidea) und ihre morphologischmetrische Variabilität. Zeitschrift für Parasitenkunde 25, 359-370.

ERGENs, R. (1983). Gyrodactylus from Eurasian freshwater Salmonidae and Thymallidae. Folia Parasitologica 30, 15-26.

IESHKo, E. P., BERLAND, B., SHUlMan, S., BRISTOW, G. A. \& Shurov, I. L. (1995). Parasites of Atlantic salmon parr in some Karelian rivers flowing into the White Sea. Abstract of the Fourth International Symposium of Ichthyoparasitology, Munich, Germany, October, p. 100.

Imamovic, v. (1987). Paraziti i parazitoze riba u nekim Salmonidnim ribogojilistima u Bosni i Hercegovini. III. Girodaktiloza. (Parasites and parasitoses of fishes in some salmonid fish ponds in Bosnia-Herzegovina). Veterinaria 36, 159-166. (In Serbo-croat.)

JOHNSTON, C., Mackenzie, K., CUNNINGHAM, C. O., EIRAs, J. C. \& BRUNO, D. W. (1996). Occurrence of Gyrodactylus salaris Malmberg, 1957, in Portugal. Bulletin of the European Association of Fish Pathologists 16, 89-91.

KAY, J. W., SHinN, A. P. \& SOMMERVille, C. (1999). Towards an automated system for the identification of notifiable pathogens. Parasitology Today 15, 201-206.

Kulakovskaya, O. P. (1967). Fragments on the parasite fauna of fishes from the upper course of the Rivers Tisa and Seret. Helminthologia 8, 289-295.

Llewellyn, J. (1970). Monogenea. In Technical Review: Taxonomy, Genetics and Evolution of Parasites. Second International Congress of Parasitology. Fournal of Parasitology 56, 493-504.

Lux, E. (1990). Gyrodactylus salaris - Parasitierung von Salmoniden, ein diagnostisch - taxonomisches Problem. Tagung der Fachgruppe 'Fischkrankheiten' in Verbindung mit der EAFP/Deutsche Sektion European Association of Fish Pathologists, 14-16 November, 1990. pp. 87-98.

MALMBERG, G. (1957). [On the occurrence of Gyrodactylus on Swedish fishes.] Skrifter utgivna av Södra Sveriges Fiskeriförening Årsskrift 1956, 19-76 (In Swedish with an English summary).

MALmBerg, G. (1970). The excretory systems and marginal hooks as a basis for the systematics of Gyrodactylus (Trematoda, Monogenea). Arkiv för Zoologi, Serie 2, 23, 1-235.

MALMBerg, G. (1973). Gyrodactylus infestations on species of Salmo in Danish and Swedish hatcheries. Norwegian Fournal of Zoology 21, 325-326.

MALMBERG, G. (1987a). Increased intraspecific divergence in Gyrodactylus salaris resulting from 
genetic drift in fish farm populations. Information, Åbo Akademii 19, 33.

MALMBerG, G. (1987b). Gyrodactylus salaris Malmberg, 1957 and G. truttae Gläser, 1974 - two problematic species. Information, Abo Akademii 19, 34.

MALMBERG, G. $(1987 c)$. Gyrodactylus - en haptormask av ekonomiskt interesse for fiskodlare. Vattenbruk 2, 15-20.

MALMBERG, G. (1993). Gyrodactylidae and gyrodactylosis of Salmonidae. Bulletin Français de la Pêche et de la Pisciculture 328, 5-46.

mclachlan, G. J. (1992). Discriminant Analysis and Statistical Pattern Recognition. Wiley, Chichester and New York.

MO, т. А. (1983). Gyrodactylus truttae Gläser, 1975, på ørret, Salmo trutta L. og laks Salmo salar L. i Sanvikvassdraget. Taksonomi og infeksjonsforhold Hovedfagsoppgave i spesiell zoologi. Thesis, University of Oslo, Zoologisk Museum.

мо, т. А. (1991 a). Seasonal variations of opisthaptoral hard parts of Gyrodactylus salaris Malmberg, 1957 (Monogenea: Gyrodactylidae) on parr of Atlantic salmon Salmo salar L. in the River Batnfjordselva, Norway. Systematic Parasitology 19, 231-240.

мо, т А. (1991 b). Variations of opisthaptoral hard parts of Gyrodactylus salaris Malmberg, 1957 (Monogenea: Gyrodactylidae) on rainbow trout Oncorhynchus mykiss (Walbaum, 1792) in a fish farm, with comments on the spreading of the parasite in south-eastern Norway. Systematic Parsitology 20, 1-9.

мо, т. А. $(1991 c)$. Variations of opisthaptoral hard parts of Gyrodactylus salaris Malmberg, 1957 (Monogenea: Gyrodactylidae) on parr of Atlantic salmon Salmo salar L. in laboratory experiments. Systematic Parasitology 20, 11-19.

мо, т. А. (1994). Status of Gyrodactylus salaris problems and research in Norway. In Parasitic Diseases of Fish, (ed. Pike, A. W. \& Lewis, J. W), pp. 43-56. Samara Publishing Ltd, Dyfed.

MO, T. A. \& APPlEBY, C. (1990). A special technique for studying haptoral sclerites of monogeneans. Systematic Parasitology 17, 103-108.

Platten, M., Mcloughlin, M. \& Shinn, A. P. (1994). Distribution and identification of gyrodactylid species in fish farms and rivers of Northern Ireland. Veterinary Record 135, 411-412.

REHUlKa, J. (1973). Remarks on the occurrence of Gyrodactylus salaris Malmberg, 1957 sensu Ergens, 1961 (Monogenoidea: Gyrodactylidae). Vestnik Ceskoslovenské Spolecnosti Zoologické 37, 293-295. RIMAILA-PÄRNÄNEN, E. \& WIKLUND, T. (1987).

Gyrodactylus salaris - loismadon levinneisyydestä makeanveden kalanviljelylaitoksissamme. Suomen Eläinlääkärilehti 93, 506-507.
RUMyAnTSEV, E. A. (1989). Some aspects in the studies of fish parasite fauna in the lakes of different type. In Bauer, O. N. (Ed). Parasites of Freshwater Fishes of $N$. W. Europe (ed. Bauer, O. N.) (Materials of the International Symposium of Soviet-Finnish Cooperation, 10-14 January, 1988), pp. 123-130.

SANTAMARINA, M. T., TOJO, J., UBEIRA, F. M., QUiNTEIRO, P. \& SANMARTIN, M. L. (1991). Anthelminthic treatment against Gyrodactylus sp. infecting rainbow trout Oncorhynchus mykiss. Diseases of Aquatic Organisms 16, 39-43.

SCHMAHL, G. (1988). Chemotherapy and control (Gyrodactylus and Pseudodactylogyrus). First International Symposium on Monogenea, 7-13 August, Ceské Budejovice, Czechoslovakian Academy of Sciences, p. 49.

SHINN, A. P. (1994). The application of new biosystematic techniques in the discrimination of the genus Gyrodactylus (Monogenea) on salmonoid fish. Ph.D. thesis, University of Stirling.

SHINN, A. P., DES CleRS, S. A., GIBSON, D. I. \& SOMMERVILLE, C. (1996). Multivariate analysis of morphometrical features from Gyrodactylus spp. (Monogenea) parasitising British salmonids: Light microscope based studies. Systematic Parasitology 33, 115-125.

SHINN, A. P., GiBSon, D. I. \& SOMMERVILle, C. (1993). An SEM study of the haptoral sclerites of the genus Gyrodactylus Nordmann, 1832 (Monogenea) following extraction by digestion and sonication techniques. Systematic Parasitology 25, 135-144.

ShinN, A. P., KaY, J. W. \& SOMmerville, C. (2000). The use of statistical classifiers for the discrimination of species of the genus Gyrodactylus (Monogenea) parasitising salmonids. Parasitology 120, 261-269.

SHINN, A. P., SOMMERVILle, C. \& GIBSON, D. I. (1995). Distribution and characterization of species of Gyrodactylus Nordmann, 1832 (Monogenea) parasitizing salmonids in the $\mathrm{UK}$, and their discrimination from G. salaris Malmberg, 1957. Fournal of Natural History 29, 1383-1402.

s-Plus 4. (1997). Seattle: Data Analysis Products Division, Mathsoft.

TANUM, K. (1983). Studier av taksonomi og vertsforhold hos Gyrodactylus - arter på laksefisk av slektene Salmo og Salvelinus I Norge-Hovedfagsoppgave i spesiell zoologi. Thesis, University of Oslo.

TESARCIK, J. \& IVASIK, v. (1974). Comparison of the helminth fauna of trouts in the River Moravice and in carpathian ponds. Helminthologia 15, 773-778.

venables, w. N. \& Ripley, B. D. (1997). Modern Applied Statistics with S-Plus. Springer-Verlag, Berlin.

ZITNAN, R. (1974). Acclimatization of fish in the carpathian region of Czechoslovakia and the role of helminths in this process. Ichthyologia 6, 143-155. 